University of Missouri, St. Louis

IRL@UMSL

$11-3-2014$

\title{
Assessing the Monitoring and Management of Overweight and Obesity in Children Hospitalized for Asthma
}

Anne E. Borgmeyer

University of Missouri-St. Louis, aeb726@umsl.edu

Follow this and additional works at: https://irl.umsl.edu/dissertation

Part of the Nursing Commons

\section{Recommended Citation}

Borgmeyer, Anne E., "Assessing the Monitoring and Management of Overweight and Obesity in Children Hospitalized for Asthma" (2014). Dissertations. 217.

https://irl.umsl.edu/dissertation/217

This Dissertation is brought to you for free and open access by the UMSL Graduate Works at IRL @ UMSL. It has been accepted for inclusion in Dissertations by an authorized administrator of IRL @ UMSL. For more information, please contact marvinh@umsl.edu. 
Assessing the Monitoring and Management of Overweight and Obesity in Children Hospitalized for Asthma

\author{
Anne E. Borgmeyer \\ M.S., Nursing of Children, University of Missouri - Kansas City, 1977 \\ B.S., Nursing, St. Louis University, 1975 \\ A Doctor of Nursing Practice Project submitted to the Graduate School at the \\ University of Missouri - St. Louis in partial fulfillment of the requirements for the degree \\ Doctor of Nursing Practice
}

October 2014

Advisory Committee

Susann Farberman, DNP, MEd, CPNP-PC Chairperson

Nancy Magnuson, DSN, CS, FNP-BC

Robert Strunk MD

Rick Yakimo, PhD, RN, PMHCNS-BC, N-NAP 


\begin{abstract}
Asthma and overweight are two of the most common chronic health problems in children. Data support a relationship between the two health issues. Although asthma is one of the top reasons for hospital admission for children, little is known about the prevalence of overweight and obesity or clinical practice related to weight in children hospitalized for asthma. The purpose of this project was to assess weight characteristics of children admitted with asthma, as well as the current practices of monitoring and management of overweight and obesity in children hospitalized with asthma. A retrospective review of medical records was conducted. The sample consisted of 510 subjects aged 3 to 17 who were admitted to a pediatric hospital in the Midwest with a primary diagnosis of asthma in 2012. ANOVA, Chi-Square and Fisher's Exact Test were used for analysis.
\end{abstract}

The results showed the weight distribution for the sample to be similar to that of the general population. Age differed statistically by weight group $(p<0.001)$. Healthy weight participants were younger than overweight participants $(p=0.008)$ and obese participants $(p<$ 0.001). The relationship of chronic asthma severity and weight group was significant in the older age category $(p=0.033)$. Comparison of acute severity and weight group was not statistically significant. Documentation of Body Mass Index (BMI) percentile was missing in 493 (96.7\%) of the records. Providers documented BMI percentile for $11 \%$ of the subjects with obesity but it was not documented for any of the 68 subjects with overweight (0\%). Only $5.4 \%$ of the subjects with overweight or obesity were given a discharge diagnosis indicating overweight or obesity and only $8.3 \%$ received counseling or treatment for weight management.

In conclusion, there was significant lack of recognition, diagnosis and treatment of overweight and obesity in children hospitalized with asthma. Asthma severity increased as BMI 
percentile increased, but only in the older subjects. This study supports the importance of weight recognition and management in the care of children with asthma. The results will be the basis for planning and implementing practice change to improve the care of children hospitalized with asthma who are overweight or obese.

Key words: pediatric asthma, childhood obesity, inpatient asthma 


\section{Acknowledgements}

I would like to thank Dr. Susann Farberman for her guidance throughout this project. Dr. Farberman's support gave me the encouragement that I needed to enter into the DNP program and to conduct and complete this project. I am also indebted to my committee members, Dr. Rick Yakimo and Dr. Nancy Magnuson, who were available and helpful from the beginning to the completion of the project. A special thanks to Dr. Robert Strunk who was not only patient with my many questions and provided the clinical expertise to ensure the relevance and accuracy of this project, but who has been a clinical mentor for me over the past 20 years.

I am grateful for the support that I received from the administration and my colleagues at the hospital. Without their support, and the help of all the key stakeholders, I would not have been able to conduct this study. I feel privileged to work with a dedicated group of professionals that embraced my wish to study this important health issue and shared my hope of improving the care of children who have asthma and overweight. Although many at the hospital deserve my thanks, Dr. Karen Balakas and Ms.Angela Niesen have been invaluable and deserve a special word of gratitude. Dr. Balakas, Director of Research, was a wonderful resource for me and served as a sounding board throughout this project. Dr. Balakas was also instrumental in helping me to apply for the grant funding and getting me through the IRB process. Ms. Angela Niesen and Dr. Patrick Ercole helped with data and data analysis and I could not have gotten the project finished without their help. Thanks, also, to Dr. Abby Hollander for providing me with her expertise in the care of children with overweight and obesity and for her help in planning for this project.

Finally, I would like to thank my family, especially my husband. I don't think anyone in the family thought that I would go back to school after almost 40 years. The Doctor of Nursing 
Practice program and this project definitely impacted our whole family, and their patience and support was certainly appreciated. Truly the Doctor of Nursing Practice is the culmination of learning the practice of nursing that began when I entered nursing school in 1971 and my family has been by my side every step of the way. 


\section{Table of Contents}

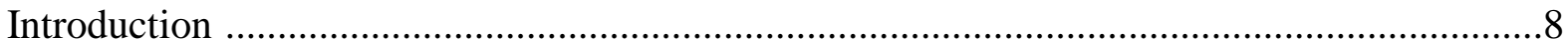

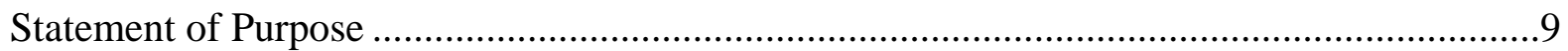

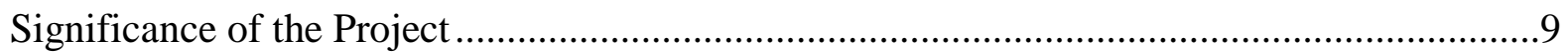

Theoretical Framework............................................................. 10

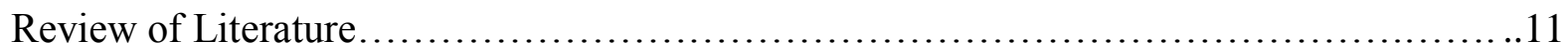

Pediatric Asthma.............................................................. 11

Pediatric Overweight and Obesity....................................... 12

Relationship of Asthma and Obesity .......................................................... 14

Need for the Project................................................................. 15

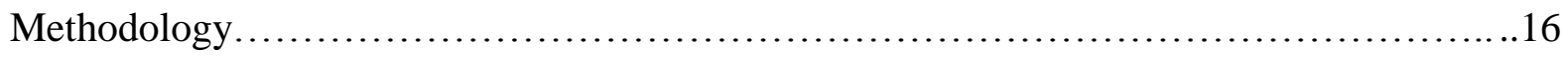

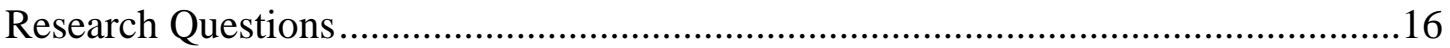

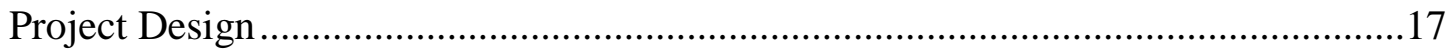

Data Analysis........................................................... 20

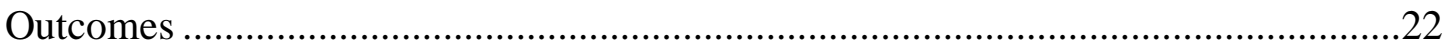

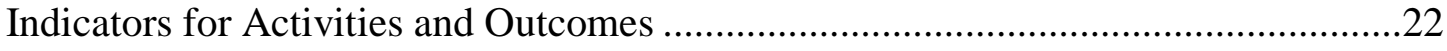

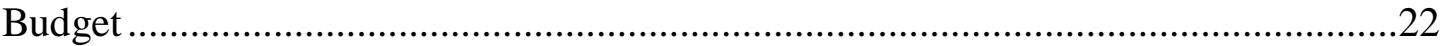

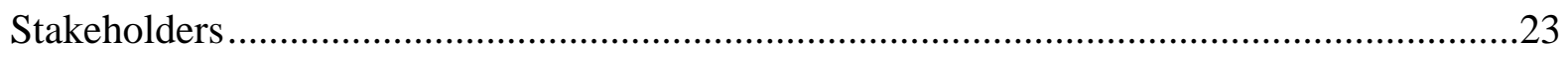

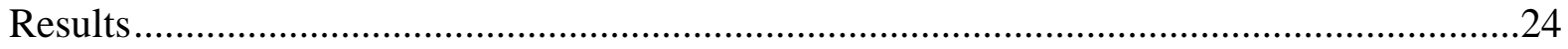

Demographic Factors.................................................. 24

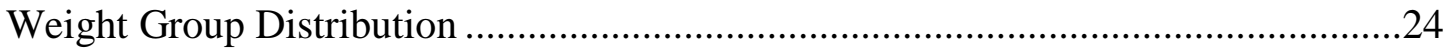

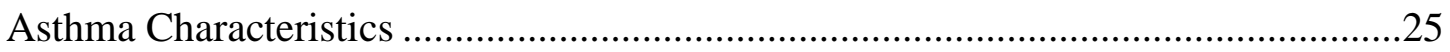

Recognition of BMI Percentile and Diagnosis of Overweight and Obesity...........29 


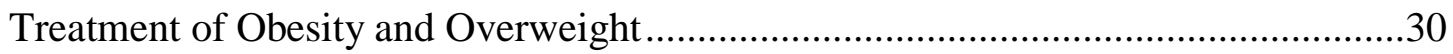

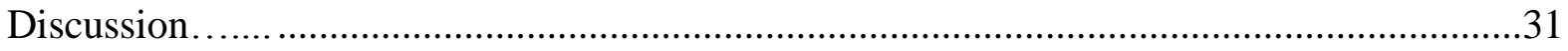

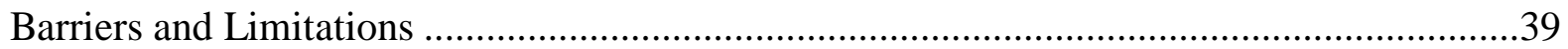

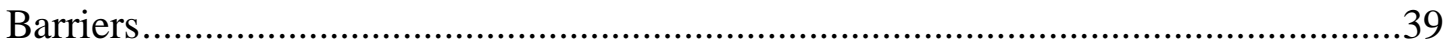

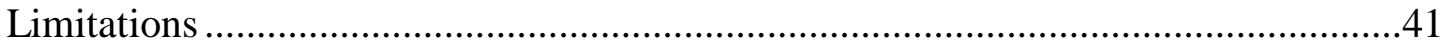

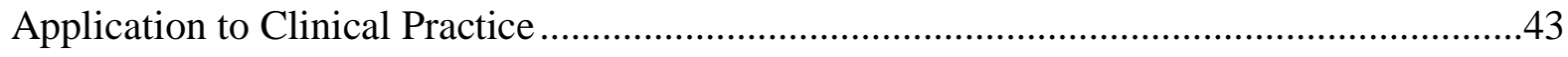

Application of the Essentials of Doctoral Education for Advanced Nursing Practice.........43

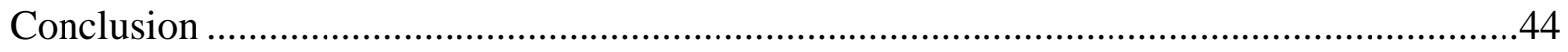

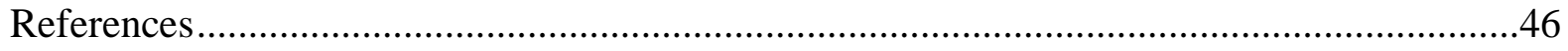

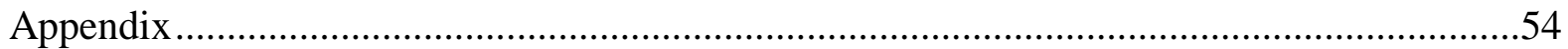




\section{Introduction}

Asthma and overweight are two of the most common chronic health problems in children. According to data from the National Surveillance of Asthma from 2008 to 2010, the prevalence for asthma in children less than 18 years was 9.5\% (Moorman, et al., 2012). Even more remarkable is a report from the Center for Disease Control and Prevention (CDC), based on the data from the National Health and Nutrition Examination Survey, that $17 \%$ of youth in the United States were obese in that same time period (Ogden, Carroll, Kit, and Flegal, 2012). National data on the prevalence of children with both asthma and obesity are not available, but there are data that demonstrate a relationship between asthma and obesity (Gilliland, et al., 2003; Sithole, Douwes, Burstyn, \& Veugelers, 2008). While there are guidelines for the management of asthma in the inpatient and outpatient setting, there is lack of attention to monitoring and managing childhood overweight and obesity as contributing factors in those guidelines (The Joint Commission, 2011; National Heart Lung Blood Institute [NHLBI], 2007).

In the United States (U.S.) in 2006 there were 335,000 asthma related admissions for children less than 18 years for asthma and 137,700 of these admissions had a primary diagnosis of asthma (Merrill, Stranges, \& Steiner, 2008). There is evidence that children admitted for asthma have higher prevalence of obesity than the general population. For example, Carroll, Bhandari, Zucker, and Schramm (2006) found an association between obesity and asthma severity in critically ill children with status asthmaticus. Ginde, Santillan, Clark, and Carmargo (2010) stated, "Regardless of the causal nature of the association between obesity and asthma, the high prevalence of children with comorbid obesity and asthma is an important public health problem" (p. 485). 


\section{Statement of Purpose}

The purpose of this retrospective review of medical records is to: (a) establish the prevalence of overweight and obesity in children aged 3 to 17 years admitted with asthma to a pediatric hospital in the Midwest, (b) determine if there is a difference in the severity of chronic asthma symptoms and/or the severity of the acute episode among children hospitalized with asthma who are underweight, healthy weight, overweight or obese, (c) determine if Body Mass Index (BMI) percentile is recognized for children hospitalized for asthma, (d) determine the frequency with which children with asthma who are overweight or obese are given the discharge diagnosis of overweight or obesity in addition to the diagnosis of asthma, and (e) describe the treatment of overweight or obesity for children hospitalized with asthma.

\section{Significance of the Project}

Literature describes a relationship between asthma and obesity (Gilliland, et al., 2003; Sithole, Douwes, Burstyn, \& Veugelers, 2008) and studies have demonstrated that weight management improves asthma symptoms and quality of life for children with asthma (Jenson, Gibson, Collins, Hilton, \& Wood, 2013). Although recent studies have shown that a growing proportion of children with asthma are cared for in emergent and acute care settings (Akinbami, Moorman \& Liu, 2011), the current recommendations for prevention and management of overweight and obesity by the Expert Committee on the Prevention and Treatment of Childhood Obesity (The Expert Committee) focus on the primary care setting (Barlow, 2007). Little is known about the prevalence of overweight and obesity in children admitted with asthma, or the current practice to monitor and manage overweight or obesity in in these patients. Providers that overlook overweight and obesity during admission for asthma are potentially missing a window of opportunity to not only improve asthma symptoms, but prevent further development of 
overweight and obesity that may lead to a multitude of future chronic health issues. The goal of this project was to assess the weight characteristics of children admitted to the hospital with asthma and the clinical practice for monitoring and managing overweight and obesity in the inpatient setting. The results of the project will be the basis for planning and implementing practice changes to improve the care of these children.

\section{Theoretical Framework}

Kurt Lewin’s Change Management Model (1974) guided this project. Lewin’s model describes the change process in three steps: unfreeze, change and refreeze. In applying the first stage of Lewin's model, the current practice is broken down to lay the groundwork for practice change. Data about the prevalence of overweight and obesity in children hospitalized with asthma were necessary to establish the foundation for changing or unfreezing the current practice. It was anticipated that the results of this project would demonstrate under-recognition of overweight and obesity, the impact of weight on the severity of chronic and acute asthma, and the lack of weight management in current practice. As such, the results will support the need to unfreeze the current practice and prepare the organization for change. Change is the second stage of Lewin's model. The results from this project will present the organization with evidence that the practice change is necessary and motivate the stakeholders to develop a new model by incorporating recognition and management of overweight and obesity into the practice guidelines for children admitted with asthma. Once the new practice guideline is developed and implemented, the third stage of refreeze will be necessary to solidify the new practice as standard of care in the organization. Refreezing may involve incorporating the new practice guideline into the electronic order set, educating the staff and providers, and tracking quality metrics to assess the use of and effectiveness of the practice change. 


\section{Review of the Literature}

A comprehensive review of the literature related to asthma and obesity in children was done. Key words for this literature review include asthma, obesity, pediatric, childhood, childhood asthma and obesity, body mass index, inpatient, management, guidelines, hospitalized children, and quality. This review of literature addresses pediatric asthma, pediatric overweight and obesity, the relationship of asthma and obesity, and quality metrics.

\section{Pediatric Asthma}

Asthma affects more than 9 million children in the U.S. and prevalence increased $1.4 \%$ per year between 2001 and 2010 (Moorman et al., 2012). Also increasing is the number of children who seek urgent and acute care for asthma (Akinbami, Moorman \& Liu, 2011). The NHLBI (2007) promotes use of the expert panel guidelines for managing the care of children with asthma in the primary care and inpatient settings. The 2007 NHLBI best-practice approaches are based on a systematic review of published medical literature and information regarding childhood asthma and is expanded compared to earlier versions of the guidelines. The NHLBI guidelines stress the importance of asthma control and include best practice for diagnosing asthma, assessing severity and control, and prescribing medications based on a stepwise approach. Advice is given for controlling environmental triggers and co-morbid diseases that can cause asthma symptoms to be worse. Recommendations are given for testing, patient education, and frequency of follow-up, and the Asthma Action Plan is recommended as a tool for patient self-management and education. Missing in the NHLBI guidelines are any recommendations related to management of weight in children with asthma.

For children with asthma who are hospitalized, The Joint Commission (2011) developed the Children's Asthma Care (CAC) quality performance measures which address the use of 
albuterol and systemic steroids during admission, provision of a scheduled appointment for follow-up with the primary care provider, and creation of an individualized home management plan of care as part of the discharge instructions. Fassl et al. (2012) demonstrated that implementing the CAC quality measures resulted in a sustained decrease in hospital asthma readmission rates. Many successful pediatric hospitals utilize inpatient pathways to promote consistent, evidence-based asthma care, improve patient and family asthma education, contain cost, and monitor outcomes (Banasiak \& Meadows-Oliver, 2004; Borgmeyer, Gyr, Jamerson, \& Henry, 2008; Cincinatti Children's Hospital Medical Center , 2010). Most pathways are now incorporated into computerized provider order entry systems resulting in improved adherence to guidelines for asthma care (Chisolm et al., 2006; McAlearney, Chisolm, Veneris, Rich, \& Kelleher, 2006; Munasinghe, Arsene, Abraham, Zidan, \& Siddique, 2011). Monitoring CAC quality outcomes has become a critical part of assuring adherence to best practices in asthma care. However, there is no mention of weight management for children with asthma in the CAC quality performance measures.

\section{Pediatric Overweight and Obesity}

Like asthma, childhood obesity is also increasing and has nearly tripled since 1980 (Ogden \& Carroll, 2010). Approximately one in three children aged 2 to 19 years are overweight or obese (Ogden, 2012). The American Medical Association, in collaboration with the Health Resources and Service Administration and the CDC, convened The Expert Committee to review the literature and develop a practical approach for providers to address childhood overweight and obesity (Barlow, 2007). The Expert Committee defined underweight as body mass index (BMI) less than $5^{\text {th }}$ percentile; healthy weight as BMI $5^{\text {th }}$ to $84^{\text {th }}$ percentile; overweight as body mass index BMI $85^{\text {th }}$ to $94^{\text {th }}$ percentile and obesity as BMI equal to or greater than $95^{\text {th }}$ percentile. 
The Expert Committee recommendations for prevention and management of overweight focus on primary care and school settings and include a four-stage approach (Barlow, 2007; Rao, 2008) The stages include limiting consumption of sweetened beverages and fast food, limiting screen time, encouraging physical activity for 60 minutes per day, and encouraging family meal time most days of the week. The Expert Committee also developed an algorithm to assess obesity risk and outlined steps for prevention and treatment (Barlow, 2007). Identifying, plotting and monitoring the BMI are essential steps in the algorithm (Murray \& Battista, 2009) but studies have shown that primary care providers, even when aware of the guidelines, are failing to measure and monitor BMI (Larsen, Mandleco, Williams, \& Tiedeman, 2006; Tanda \& Salsberry, 2014).

This review found that there was even less emphasis on BMI monitoring in the inpatient setting, where guidelines may include weight measurement but do not routinely address calculating and plotting the BMI. Sleeper, Ariza, and Binns (2009) studied children admitted to a tertiary hospital and determined that only $35 \%$ of patients had their BMI calculated, only $54 \%$ of the patients who were overweight received an evaluation by a nutritionist, and only $1.3 \%$ of patients who were obese had a discharge diagnosis that included overweight or obesity. Young et al. (2011) reported that a survey of National Association of Children's Hospitals and Related Institutions (NACHRI) member hospitals found that $63 \%$ of responding hospitals did not have policies in place to identify patients with obesity. It was recommended that hospitals adapt BMI recording practices as a "first step in addressing childhood obesity" (Young et al., p. S49).

\section{Relationship of Asthma and Obesity}

In the adult population, there are studies that demonstrate an increased prevalence of asthma subjects who are overweight or obese when compared with the general population 
(Shaheen, Sterne, Montgomery \& Azima, 1999; Carmargo, Weiss, Zhang, Willett \& Speizer, 1999). Taylor et al. (2008) reported that obesity and asthma in adults led to more symptoms, increased use of medication, and more missed work days. There are also studies in children that link asthma and obesity and demonstrate that asthma prevalence and incidence are increased by the presence of obesity in children (Gilliland et al., 2003; Gold, Damokosh, Dockery, \& Berkey, 2003; Cottrell, Neal, Ice, Perez, \& Piedimonte, 2011). Quinto et al. (2011) found that overweight and obese children were more likely to have increased beta agonists and oral steroids dispensed than normal weight children. Studies have also been published demonstrating that the prevalence of obesity is significantly higher in children who present to the Emergency Department with asthma (Ginde, et al., 2010; Sah, Teague, Demuth, Whitlock, Brown \& Fitzpatrick, 2013); and that overweight children who present to the emergency department with asthma are more likely to be admitted (Carroll, Stoltz, Raykov, Smith, and Zucker, 2007). Carroll, et al., (2006) studied patients admitted to the pediatric intensive care unit and found that obese children had longer length of stay and received longer courses of steroids, supplemental oxygen, continuous albuterol and intravenous steroids.

Despite an apparent relationship between asthma and obesity, the cause of the relationship is not yet clear. Restriction of breathing due to excess body weight, de-conditioning due to inactivity, and production of pro-inflammatory cells or hormones due to adiposity are proposed as mechanisms that may cause increased asthma symptoms in overweight or obese children however studies have not been conclusive (Ginde, et al., 2010; Jenson, Collins, Gibson, \&Wood, 2011; Jenson, Wood, \& Gibson, 2012). Regardless of cause, the problem of obesity and asthma demands the attention of health care providers. A recent study by Jenson, Gibson, Collins, Hilton, \& Wood (2013) demonstrated that losing weight by diet change resulted in 
significant improvements in asthma symptoms for obese children. Health disparities based on economic and ethnic differences also present challenges to practice. Obesity and asthma are both more prevalent in lower income groups as well as in the black and Latino populations (Moorman et al, 2007; Moorman et al., 2012; Flores et al., 2009). Access to care drives families in these lower income groups to utilize hospital care instead of primary care. As stated by Orzag and Emanuel (2010), health care reform calls "providers to consistently improve outcomes, boost quality, and reduce costs". In an era of health care reform, providers are called upon to develop cost-conscious approaches to caring for children with obesity and asthma to improve quality of life, decrease symptoms, and prevent future costly health issues. Development of policy and coordination of overweight and obesity screening efforts in all health settings has the potential to impact the overall health of children but, more specifically, the health care of children with asthma.

\section{Need for the Project}

Asthma and obesity are two of the most common chronic health conditions in the pediatric population and there are data that demonstrate a relationship between the two conditions, yet little is known about weight status in children admitted to the hospital with asthma (Papoutsakis et al., 2013; Rance, 2011). For children admitted to the hospital with asthma, it is not known if obesity impacts the severity of the admission, if providers recognize and diagnose obesity, or if children are given appropriate instructions for weight management at the time of discharge. Current inpatient asthma practice guidelines do not include prevention or management of overweight and obesity (The Joint Commission, 2011; NHLBI, 2007). Baseline data are needed to determine characteristics of current practice regarding asthma and obesity in 
hospitalized children to support the need for changing the practice guidelines to include recognition and treatment of overweight and obesity.

\section{Methodology}

\section{Research Questions}

This study seeks to answer the following questions regarding children aged 3 to 17 admitted to a children's hospital in the Midwest for treatment of an exacerbation of asthma in 2012:

1. What was the prevalence of underweight (BMI less than $5^{\text {th }}$ percentile), healthy weight (BMI $5^{\text {th }}$ to $84^{\text {th }}$ percentile), overweight (BMI $85^{\text {th }}$ to $94^{\text {th }}$ percentile), and obesity (BMI $95^{\text {th }}$ percentile and greater) in subjects for the study period January 1, 2012 to December $31,2012 ?$

2. Is there a difference in chronic asthma severity or severity of the acute episode among children who are underweight (BMI less than $5^{\text {th }}$ percentile), healthy weight (BMI $5^{\text {th }}$ to $84^{\text {th }}$ percentile), overweight (BMI $85^{\text {th }}$ to $94^{\text {th }}$ percentile) or obese (BMI $95^{\text {th }}$ percentile and greater)?

3. What was the percentage of electronic health records lacking documentation of BMI percentile?

4. What percentage of patients with overweight (BMI $85^{\text {th }}$ to $94^{\text {th }}$ percentile) or obesity $\left(\mathrm{BMI} 95^{\text {th }}\right.$ percentile or greater) did not have a diagnosis of overweight or obesity listed in the discharge instructions in addition to the diagnosis of asthma?

5. What percentage of children with overweight (BMI $84^{\text {th }}$ to $94^{\text {th }}$ percentile) and obesity $\left(\mathrm{BMI} 95^{\text {th }}\right.$ percentile or greater) were counseled regarding healthy eating and/or exercise or were referred to a weight management program? 


\section{Project Design}

Setting and sample. This study was a retrospective cross-sectional study using data extracted from the electronic medical records of children aged 3 to 17 years admitted to a 250 bed children's hospital in the Midwest from January 1, 2012 to December 31, 2012. The children's hospital is part of an academic medical center. All male and female children with a primary diagnosis of asthma were included. Only the first admission for each subject during the study period was included in the sample.

Data collection. The study team included the primary investigator, a member of the hospital Quality Team that assisted in data collection and analysis, a physician mentor, and a staff nurse who assisted in data collection. The electronic medical records were queried and identified 569 subjects admitted with a primary diagnosis of asthma aged 3 to 17 years in the calendar year 2012. Subjects with vocal cord dysfunction, bacterial pneumonia, cystic fibrosis, bronchopulmonary dysplasia, sickle cell disease or other chronic disease affecting growth or pulmonary status were excluded from the sample to avoid diagnoses that would alter the course

of asthma treatment or make the diagnosis of asthma uncertain. Thirty-six subjects were removed from the sample based on these exclusion criteria. In addition, 23 subjects were removed due to lack of weight and/or height measurement or implausible growth data. Figure 1 describes the flow of participation in the project.

Records were de-identified to assure anonymity of the patients. All paper and electronic files were kept in a locked file cabinet in a locked office. The analytic team members completed mandatory human subject's education. The computer program used to collect data was password-protected and was not able to be accessed by anyone other than the study team 
members. Due to the retrospective nature of the chart review there was no contact of any of the participants.

Figure 1

Flow of Participants

569 unique subjects age $3-17$ years with asthma as primary discharge diagnosis in 2012

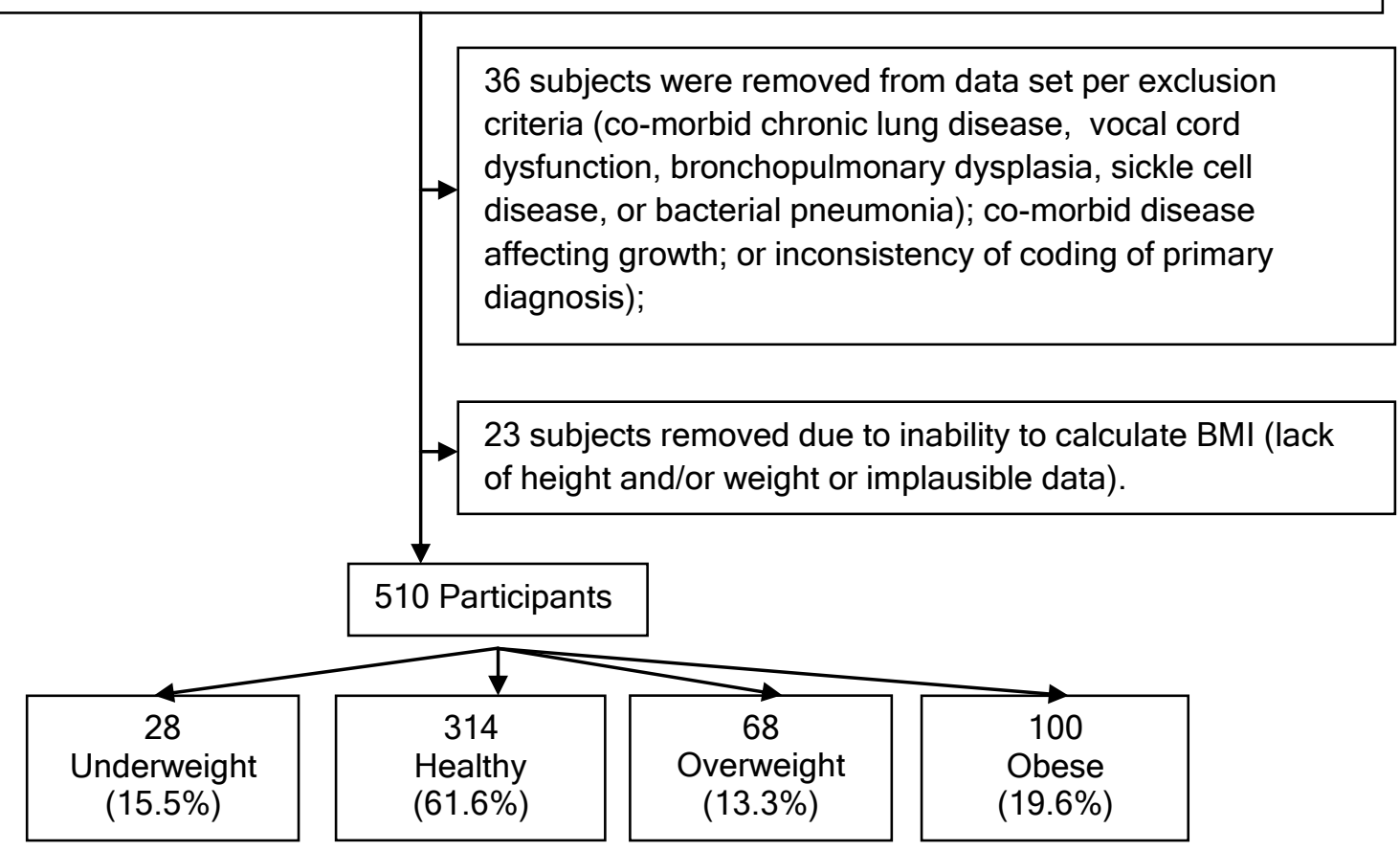

The study team utilized SPSS version 21.0 to organize the data for evaluation. Primary data collection was utilized to gather quantitative data for the baseline evaluation. The electronic medical record was queried to gather the date of birth, age, gender, race, insurance source, chronic asthma severity, overall length of stay, length of stay in the intensive care, primary and secondary discharge diagnoses, order for dietitian consult or dietitian consult note, height, and weight. The BMI and BMI percentile were calculated by the primary investigator based on height, weight, age, and gender of the subject using the online CDC BMI calculator (CDC, 2000). Subjects were grouped by CDC guidelines for weight categories (Barlow, 2007) as 
follows: BMI $<5^{\text {th }}$ percentile was considered underweight; BMI $5^{\text {th }}$ to $84^{\text {th }}$ percentile was considered healthy weight; BMI $85^{\text {th }}$ to less than $95^{\text {th }}$ percentile was considered overweight; and BMI $95^{\text {th }}$ percentile or greater was considered obese.

Severity of the acute episode and chronic severity were compared among weight categories of underweight, healthy weight, overweight and obese. Overall length of stay (LOS) and admission to the pediatric intensive care unit (PICU) served as the indicators of the severity of the acute episode. Three categories of length of stay were determined: 0-1 day, 2-3 day and 4 or more days. The indicators for chronic asthma severity were the categories as defined by the National Asthma Education and Prevention Program (NAEPP) Asthma Guidelines (NHBLI, 2007): intermittent, mild persistent, moderated persistent, and severe persistent. Chronic asthma severity was determined by the provider during the admission and documented electronically in the discharge instructions. All physician and nurse practitioner providers at the hospital are routinely instructed in the NAEPP asthma guidelines and chronic severity assessment.

The scanned notes in the electronic records of all subjects were reviewed manually to determine if the provider recognized the BMI percentile for the subject during the admission or at discharge. The indicator for recognition of BMI percentile was the recording of the BMI percentile by the provider in the admission note, daily progress note, discharge instructions, or discharge letter. The electronic health records of the patients with overweight and obesity were further reviewed to determine if treatment was given to the children for overweight or obesity. Treatment for obesity was defined as referral to a dietitian or consultation by a dietitian during the hospitalization or at discharge, evidence of instructions for healthy eating or exercise during the hospitalization or at discharge and referral to a weight management program at discharge. Referral to a dietitian, a healthy eating recommendation, or referral to an outpatient weight 
management program was determined by a consultation order, a dietitian note, provider note, or discharge recommendation in the electronic health record.

To assess reliability of the transcription, five random electronic charts were reviewed by the nurse research assistant and the primary investigator at the beginning, middle and end of the collection process for a total of 15 charts. Additionally, five random charts of the 168 subjects with overweight and obesity were reviewed. The data collected by manual review in the stratified sample of 20 random charts by the nurse research assistant and the primary investigator agreed $100 \%$. The data in the 20 charts were also compared by an unbiased researcher knowledgeable in asthma to assure lack of bias and reliability of the project data and there was only discrepancy in diet or exercise counseling by the provider in one chart.

Fleiss’ Kappa was run to assess agreement by the three reviewers about the presence or absence of the manually gathered study elements in the 20 random charts. Diagnosis of overweight/obesity, dietitian consultation, and recognition of BMI percentile had $100 \%$ agreement among the three reviewers. There was substantial agreement between the three reviewers regarding diet or exercise counseling by the provider $(\mathrm{K}=.747, p=0.036)$.

\section{Data Analysis}

Data were entered and analyzed utilizing SPSS version 21.0 for all descriptive and statistical analyses. The following data analytic plan was developed to address the research questions:

1. To determine prevalence of underweight, healthy weight, overweight, and obesity in children hospitalized with asthma, the number of children hospitalized with asthma in each weight category was divided by the total number of children hospitalized with asthma during the study period and multiplied by 100 . 
2. Pearson's Chi-Square with post-hoc test using a Bonferroni column comparison was used to determine if there was a statistically significant difference in chronic asthma severity and, separately, severity of acute episode among children hospitalized with asthma who are underweight, (BMI\% less than $5^{\text {th }}$ percentile), healthy weight (BMI $5^{\text {th }}$ to $84^{\text {th }}$ percentile), overweight (BMI $85^{\text {th }}$ to $94^{\text {th }}$ percentile) or obese (BMI $95^{\text {th }}$ percentile and greater). Statistical significance was pre-set at $p<0.05$. Due to the significant difference in age among the weight groups, further analysis using Fisher's Exact Test was conducted to adjust for age.

3. The frequency of missing documentation of BMI percentile was determined by dividing the number of patients hospitalized for asthma who did not have documentation of BMI in the electronic record by the total number of patients in the sample.

4. The frequency of patients with overweight (BMI $85^{\text {th }}$ to $94^{\text {th }}$ percentile) or obesity (BMI $95^{\text {th }}$ percentile or greater) that did not have a diagnosis of overweight or obesity listed in the discharge instructions was determined by dividing the number of patients that were overweight or obese but not diagnosed with overweight or obesity at the time of discharge by the total number of patients in the sample who are overweight or obese.

5. The frequency of children with overweight (BMI $85^{\text {th }}$ to $94^{\text {th }}$ percentile) and obesity (BMI $95^{\text {th }}$ percentile or greater) that were counseled regarding healthy eating and/or exercise or referred to a weight management program was determined by dividing the number of children with overweight or obesity that were counseled regarding healthy eating and/or exercise or referred to a weight management program during admission or at discharge by the total number of children in the sample who were overweight or obese. 


\section{Outcomes}

The short-term outcome of the project was to gather data to evaluate the prevalence and relationship of overweight and obesity in children hospitalized with asthma and the current practice in recognizing, preventing and managing overweight in this population. Long-term outcomes are expected to include improved recognition, diagnosis, and management of overweight for children admitted with asthma.

\section{Indicators for Activities and Outcomes}

Indicators for weight groups for children hospitalized with asthma were determined by the BMI percentiles and based on the Expert Panel recommendations (Barlow, 2007). Children with $\mathrm{BMI}<5 \%$ were classified as underweight. Children with BMI $5^{\text {th }}$ to $84^{\text {th }}$ percentile were classified as healthy weight. Children with BMI $85^{\text {th }}$ to $94^{\text {th }}$ percentile were classified as overweight. Children with BMI equal to or greater than $95^{\text {th }}$ percentile were classified as obese. Frequency of recognition of overweight or obesity was determined by the documentation of BMI and BMI percentile in the admission note, daily progress note or discharge instructions or the diagnosis of overweight or obesity documented in the discharge instructions or discharge letter. Treatment of overweight or obesity was determined by the referral to an inpatient or outpatient dietitian, documentation of instruction regarding healthy eating or exercise in the inpatient notes or discharge instructions, or documentation of referral to an outpatient weight management program.

\section{Budget}

The study setting hospital Foundation provided grant funding for the project. The grant totaled $\$ 1500.00$. Funds were used for the salary of the staff nurse that assisted in data collection and for costs related to the statistical analysis. 


\section{The Stakeholders}

The most important stakeholders are the children admitted with asthma who are overweight or obese and their families. The clinicians who specialized in the care of children with asthma and those who care for children with overweight or obesity are stakeholders in current standard of practice and changes that may occur as a result of this project. The frontline nurses, nurse practitioners, physicians, and dietitians are stakeholders involved in carrying out the practice standards of caring for children hospitalized with asthma. Community providers are important in the primary care of the patient and essential to the transition of care from hospital to home. As stakeholders, the community providers are essential in approving changes to inpatient care of their patients as well as any changes to the discharge instructions. Specialists in asthma and overweight are stakeholders involved in setting the standards for care of children admitted to the hospital and it was important to gain their approval to conduct the project. The information technology (IT) team was a stakeholder involved in gathering and analyzing the data. The care providers and quality improvement team will be stakeholders to evaluate the project and determine the specifics of change in practice and quality metrics related to asthma and overweight. If changes to practice are made based on the project results, all stakeholders will be involved in implementing the change.

All key stakeholders were contacted individually to discuss the project. The researcher informally discussed the project with frontline nurses and physicians as well as community providers to gain their input regarding the project. The input of the stakeholders was used in the planning process to formulate the project design. The final project proposal was distributed via email to all stakeholders for input prior to IRB submission and revised based on their suggestions. 


\section{Results}

\section{Demographic Factors}

Demographic characteristics of the subjects are listed below in Table 1. Five hundred ten subjects met the criteria for inclusion in the sample. Subjects ranged in age from 3 to $17(\mathrm{M}=$ $8.4, \mathrm{SD}=3.8)$. The majority of the subjects were male $(62.9 \%)$. The majority of the subjects were African American (75.9\%), with the next most prevalent race being Caucasian (19.2\%). Insurance status was used as a measure of economic status. The majority of the subjects had government health insurance $(66.7 \%)$ with the next most prevalent insurance being commercial insurance $(29.5 \%)$. There were $3.7 \%$ of subjects that were uninsured.

Table 1

Demographic Characteristics of Respondents $(N=510)$

\begin{tabular}{lrc} 
Variable & mean $/ n$ & $(\mathrm{SD}) /(\%)$ \\
\hline Age, mean (SD) & 8.4 & $(3.8)$ \\
Gender $n(\%)$ & & \\
$\quad$ Male & 321 & $(62.9)$ \\
$\quad$ Female & 189 & $(37.1)$ \\
Race/Ethnicity $n(\%)$ & & \\
$\quad$ Caucasian & 98 & $(19.2)$ \\
$\quad$ African American & 387 & $(75.9)$ \\
$\quad$ Asian & 3 & $(0.6)$ \\
$\quad$ Other & 17 & $(3.3)$ \\
$\quad$ Unknown & 5 & $(1.0)$ \\
Insurance Status & & \\
$\quad$ Government & 339 & $(66.7)$ \\
$\quad$ Commercial & 150 & $(29.5)$ \\
$\quad$ Self-pay & 19 & $(3.7)$
\end{tabular}

\section{Weight Group Distribution of the Sample According to Body Mass Index Percentile}

Research question 1. What was the prevalence of underweight (BMI less than $5^{\text {th }}$ percentile), healthy weight (BMI $5^{\text {th }}$ to $84^{\text {th }}$ percentile), overweight (BMI $85^{\text {th }}$ to $94^{\text {th }}$ percentile), 
and obesity (BMI $95^{\text {th }}$ percentile and greater) in subjects for the study period January 1,2012 to December 31, 2012?

Table 2 shows the distribution of the sample by weight group. A total of $100(19.6 \%)$ of the subjects were obese, 68 (13.3\%) were overweight, $314(61.6 \%)$ were healthy weight, and 28 $(5.5 \%)$ of the subjects were underweight.

Table 2

Weight Group Distribution of the Sample

\begin{tabular}{lcrr} 
Weight Group & BMI Percentile & $n$ & $(\%)$ \\
\hline Obese & $\geq 95^{\text {th }}$ & 100 & $(19.6)$ \\
Overweight & $85^{\text {th }}$ to $94^{\text {th }}$ & 68 & $(13.3)$ \\
Healthy Weight & $5^{\text {th }}$ to $84^{\text {th }}$ & 314 & $(61.6)$ \\
Underweight & $<5^{\text {th }}$ & 28 & $(5.5)$ \\
\hline Total & & 510 & $(100.0)$
\end{tabular}

Appendix Table A1 shows the demographic characteristics of the subjects across the weight group distribution of the sample. There were no significant differences by gender, raceethnicity, or insurance status across BMI distribution in the sample; however the data demonstrate a significant difference by age. A one-way analysis of variance (ANOVA) was conducted to detect differences in age by weight group. Patient age was found to differ statistically by weight group $(p<0.001)$. Healthy weight subjects averaged 1.7 years younger than overweight subjects $(p=0.008)$ and 2.3 years younger than obese subjects $(p<0.001)$. Underweight subjects were 3.0 years younger than overweight subjects $(p<0.001)$ and 3.6 years younger than obese participants $(p<0.001)$.

\section{Asthma Characteristics}

Research question 2. Is there a difference in chronic asthma severity or severity of the acute episode among children hospitalized with asthma who are underweight (BMI less than $5^{\text {th }}$ 
Percentile), healthy weight (BMI $5^{\text {th }}$ to $84^{\text {th }}$ Percentile), overweight (BMI $85^{\text {th }}$ to $94^{\text {th }}$ Percentile), or obese (BMI $95^{\text {th }}$ Percentile and greater)?

Chronic asthma severity. Data regarding chronic asthma severity of the sample are listed in Appendix Table A1. Nine subjects (1.8\%) were removed from the chronic severity analysis due to missing data regarding chronic asthma severity. Chronic asthma severity was classified as intermittent for $88(17.6 \%)$ of the subjects. Four hundred thirteen subjects had persistent asthma with $114(22.8 \%)$ classified as mild persistent, $211(42.1 \%)$ classified as moderate persistent, and $88(17.6 \%)$ of subjects classified as severe persistent. Using Pearson Chi Square the data show a significant difference in chronic severity by weight group $(p=0.001)$ as indicated in Table A1.

Due to the significant difference in age among the weight groups, further analysis was conducted to adjust for age. A Fisher's Exact Test was used within age category stratifications due to small expected cell sizes. Figure 2 shows increasing weight with increasing chronic asthma severity. As shown in Table 3, when the relationship of chronic asthma severity and weight group is adjusted for age category, there was a significant association between severe persistent chronic asthma and obesity for children in the oldest age group $(p=0.033)$.

Figure 2

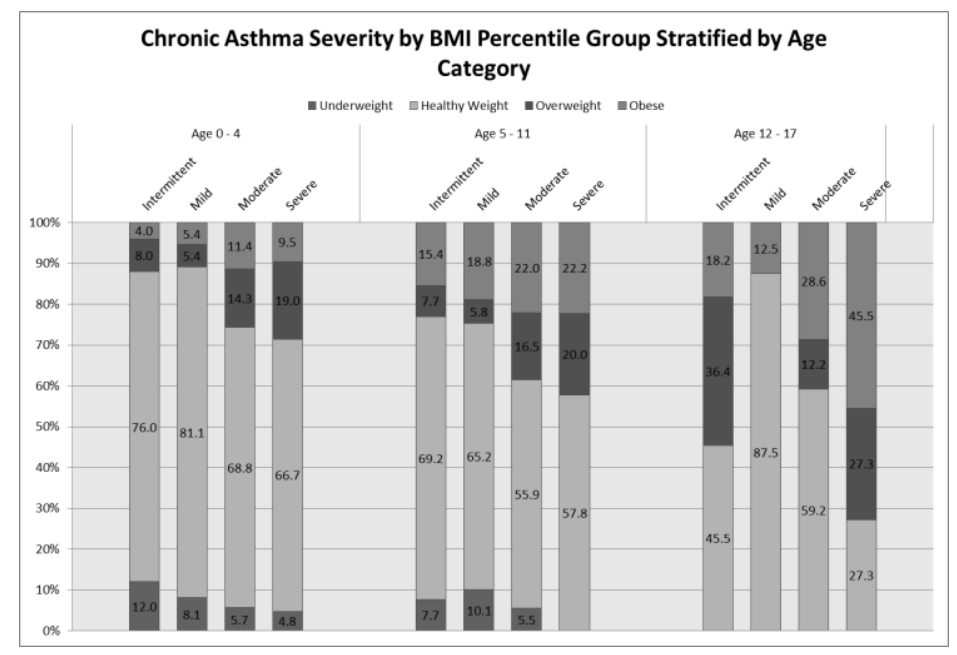


Table 3

Comparison of Chronic Asthma Severity and Weight Group Stratified by Age Group Age Chronic Asthma Severity $\left(N=501^{\mathrm{a}}\right) \quad$ CDC Weight Group

$\underline{\text { Underweight }} \underline{\text { Healthy Weight }} \underline{\text { Overweight }} \underline{\text { Obese }}$

\begin{tabular}{|c|c|c|c|c|c|c|}
\hline & & $n(\%)$ & $n(\%)$ & $n(\%)$ & $n(\%)$ & $p$-value \\
\hline \multirow[t]{5}{*}{$\overline{3-4}$} & & & & & & 0.770 \\
\hline & Intermittent & $3(12.0)$ & $19(76.0)$ & $2(8.0)$ & $(4.0)$ & \\
\hline & Mild Persistent & $3(8.1)$ & $30(81.1)$ & $2(5.4)$ & $2 \quad(5.4)$ & \\
\hline & Moderate Persistent & $2(5.7)$ & $24(68.8)$ & $5(14.3)$ & $4(11.4)$ & \\
\hline & Severe Persistent & $1 \quad(4.8)$ & $14(66.7)$ & $4(19.0)$ & $2 \quad(9.5)$ & \\
\hline \multirow[t]{5}{*}{$5-11$} & & & & & & 0.099 \\
\hline & Intermittent & $4 \quad(7.7)$ & $36(69.2)$ & $4 \quad(7.7)$ & $8(15.4)$ & \\
\hline & Mild Persistent & $7(10.1)$ & $45(65.2)$ & $4(5.8)$ & 13 (18.8) & \\
\hline & Moderate Persistent & $7 \quad(5.5)$ & $71(55.9)$ & $21(16.5)$ & $28(22.0)$ & \\
\hline & Severe Persistent & $0 \quad(0.0)$ & $26(57.8)$ & $9(20.0)$ & $10(22.2)$ & \\
\hline
\end{tabular}

$12-17$

\begin{tabular}{lrrrrr} 
Intermittent & 0 & $(0.0)$ & $5(45.5)$ & $4(36.4)$ & $2(18.2)$ \\
Mild Persistent & 0 & $(0.0)$ & $7(87.5)$ & $0(0.0)$ & $1(12.5)$ \\
Moderate Persistent & 0 & $(0.0)$ & $29(59.2)$ & $6(12.2)$ & $14(28.6)$ \\
Severe Persistent & 0 & $(0.0)$ & $6(27.3)$ & $6(27.3)$ & $10^{*}(45.5)$ \\
\hline
\end{tabular}

${ }^{\mathrm{a}} N=501$ (Nine of the 510 subjects excluded from analysis due to missing chronic severity data.)

*Obese children in the 12-17 age group are significantly different from those of healthy weight $(p=0.033)$

Severity of the acute episode. Length of stay (LOS) and admission to the pediatric intensive care unit were used as indicators of severity related to the acute episode and admission. LOS was divided into 3 groups: 1 day, 2 or 3 days, and 4 or more days. Appendix Table A1 shows the LOS by weight group. Obese patients had a lower percentage of 0-1 day LOS admission (41\%) compared to healthy weight patients with $56.4 \%$ of $0-1$ day LOS admission. Comparison of LOS by weight group using Pearson Chi Square did not demonstrate overall significance $(p=0.057)$. Table 4 shows the age adjusted comparison of LOS and weight group which also did not indicate any statistically significant associations. 
Table 4

Comparison of LOS by Weight Group Stratified by Age Group $(N=510)$

Age LOS Group

CDC Weight Group

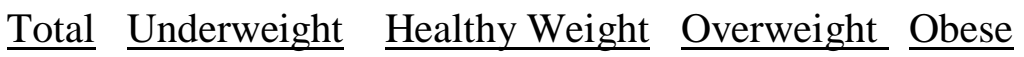

\begin{tabular}{ccccccc} 
& & $n$ & $n(\%)$ & $n(\%)$ & $n(\%)$ & $n(\%)$ \\
\hline $3-4$ & & & & & & \\
& 0-1 Day & 77 & $6(7.8)$ & $59(76.6)$ & $7(9.1)$ & $5(6.5)$ \\
2-3 Days & 36 & $2(5.6)$ & $26(72.2)$ & $6(16.7)$ & $2(5.6)$ \\
& >4 Days & 6 & $1(16.7)$ & $3(50.0)$ & $0(0.0)$ & $2(33.3)$
\end{tabular}

$5-11$

$\begin{array}{lrrrrrr}\text { 0-1 Day } & 151 & 8 & (5.3) & 99(65.6) & 19(12.6) & 25(16.6) \\ \text { 2-3 Days } & 118 & 7(5.9) & 63(53.4) & 18(15.3) & 30(25.4) \\ \geq \text { 4 Days } & 28 & 4(14.3) & 16(57.7) & 2(7.1) & 6(21.4)\end{array}$

$\begin{array}{llllrrr}\text { 0-1 Day } & 37 & 0 & (0.0) & 19(51.4) & 7(18.9) & 11(29.7) \\ \text { 2-3 Days } & 47 & 0 & (0.0) & 25(53.2) & 7(14.9) & 15(31.9) \\ \geq 4 \text { Days } & 10 & 0 & (0.0) & 4(40.0) & 2(20.0) & 4(40.0)\end{array}$

No statistical significance at $p<0.05$

Of the 510 subjects in the sample, 110 were admitted to the PICU (21.6\%). Appendix

Table A1 shows the comparison of admission to the PICU by weight group. Although a higher percentage of the subjects classified as obese were admitted to the pediatric intensive care unit (29\%) compared to the percentage of healthy weight subjects $(18.8 \%)$, the results were not statistically significant $(p=.179)$. Due to the significant difference in age among the weight groups $(p<0.001)$, the comparison of PICU status by weight group was also stratified by age group. Table 5 demonstrates that when age was adjusted, the comparisons of admission to the PICU and weight group also did not indicate any statistically significant association. 
Table 5

Comparison of PICU Status by Weight Group Stratified by Age Group $(N=510)$

Age PICU Status CDC Weight Group

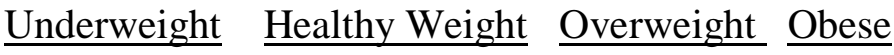

\begin{tabular}{|c|c|c|c|c|c|c|c|}
\hline \multirow{2}{*}{$\overline{3-4}$} & & \multicolumn{2}{|c|}{$n(\%)$} & \multirow[t]{2}{*}{$n(\%)$} & \multirow[t]{2}{*}{$n(\%)$} & \multirow[t]{2}{*}{$n(\%)$} & \multirow{2}{*}{$\frac{p \text {-value }}{0.218}$} \\
\hline & & & & & & & \\
\hline \multirow{5}{*}{$5-11$} & No PICU & 8 & (8.2) & $75(76.5)$ & $9 \quad(9.2)$ & $6(6.1)$ & \multirow{5}{*}{0.123} \\
\hline & PICU & 1 & (4.8) & 13 (61.9) & $4(19.0)$ & $3(14.3)$ & \\
\hline & & & & & & & \\
\hline & No PICU & 13 & (5.7) & $143(62.4)$ & $32(14.0)$ & $41(17.9)$ & \\
\hline & PICU & 6 & (8.8) & $35(51.5)$ & 7 (10.3) & $20(29.4)$ & \\
\hline
\end{tabular}

$12-17$

No PICU

$\begin{array}{lll}0 & (0.0)\end{array}$

$37(50.7)$

$12(16.4)$

$24(32.9)$

PICU

$0 \quad(0.0) \quad 11(52.4)$

$4(19.0)$

$6(28.6)$

0.946

No statistical significance at $p<0.05$

\section{Recognition of BMI Percentile and Diagnosis of Overweight and Obesity}

Research question 3. What was the percentage of electronic health records lacking documentation of BMI percentile?

Table 6 shows the data related to the documentation of BMI percentile by the provider.

Review of the records revealed that documentation of BMI percentile was missing in 493

(96.7\%) of the records. In subjects that were classified as obese, providers documented BMI

percentile for only 11 of 100 subjects (11\%), and BMI percentile was not documented for any of the 68 subjects who were overweight $(0 \%)$. 
Table 6

Frequency of Missing Documentation of BMI Percentile $(N=510)$

Weight Group Evidence of Recognition of BMI Percentile in Chart

\begin{tabular}{|c|c|c|c|c|c|}
\hline & \multicolumn{2}{|c|}{ Yes } & \multicolumn{2}{|c|}{ No } & \multirow{2}{*}{$\begin{array}{l}\text { Total } \\
n\end{array}$} \\
\hline & $n$ & $(\%)$ & $n$ & $(\%)$ & \\
\hline Obese & 11 & $(11.0)$ & 89 & $(89.0)$ & 100 \\
\hline Overweight & 0 & $(00.0)$ & 68 & $(100.0)$ & 68 \\
\hline Healthy Weight & 5 & $(1.6)$ & 309 & (98.4) & 314 \\
\hline Underweight & 1 & $(3.6)$ & 27 & $(96.4)$ & 28 \\
\hline Total & 17 & (3.3) & 493 & (96.7) & 510 \\
\hline
\end{tabular}

Research question 4. What percentage of patients with overweight $\left(\mathrm{BMI} 85^{\text {th }}\right.$ to $94^{\text {th }}$ percentile) or obesity (BMI $95^{\text {th }}$ percentile or greater) did not have a diagnosis of overweight or obesity listed in the discharge instructions in addition to the diagnosis of asthma?

As shown in Table 7, at time of discharge, 159 of the 168 subjects who were overweight or obese $(94.6 \%)$ were not given a diagnosis indicating overweight or obesity in addition to the diagnosis of asthma. The 9 patients diagnosed with overweight or obesity were all in the obese group.

Table 7

Frequency of Diagnosis of Overweight and Obesity at Discharge

Weight Group Diagnosis of Overweight or Obesity at Discharge

\begin{tabular}{|c|c|c|c|c|c|}
\hline & \multicolumn{2}{|c|}{ Yes } & \multicolumn{2}{|c|}{ No } & Tota \\
\hline & $n$ & $(\%)$ & $n$ & $(\%)$ & $n$ \\
\hline Obese & 9 & $(9.0)$ & 91 & $(91.0)$ & 100 \\
\hline Overweight & 0 & $(0.0)$ & 68 & $(100.0)$ & 68 \\
\hline Total & 9 & $(5.4)$ & 159 & $(94.6)$ & 168 \\
\hline
\end{tabular}

\section{Treatment of Obesity and Overweight}

Research question 5. What percentage of children with overweight (BMI $84^{\text {th }}$ to $94^{\text {th }}$ percentile) and obesity (BMI $95^{\text {th }}$ percentile or greater) were counseled regarding healthy eating and/or exercise or were referred to a weight management program? 
Treatment of overweight and obesity was defined as counseling regarding diet during the admission or at time of discharge or referral for outpatient counseling or weight management program as evidenced in the progress notes or discharge instructions. Table 8 shows the data for the frequency with which overweight and obese subjects were given treatment related to overweight. Of 168 overweight or obese subjects, only $14(8.3 \%)$ received treatment for obesity and overweight. All 14 of the subjects treated for overweight or obesity were in the obese weight group, therefore $14 \%$ of the obese subjects received treatment related to their obesity and $0 \%$ of the overweight subjects received treatment.

Table 8

Frequency of Treatment for Overweight and Obesity

Weight Group $\quad$ Evidence of Treatment for Overweight or Obesity

\begin{tabular}{|c|c|c|c|c|c|}
\hline & \multicolumn{2}{|c|}{ Yes } & \multicolumn{2}{|c|}{ No } & Total \\
\hline & & $(\%)$ & $n$ & $(\%)$ & $n$ \\
\hline Obese & 14 & $(14.0)$ & 86 & $(86.0)$ & 100 \\
\hline Overweight & 0 & $(0.0)$ & 68 & $(100.0)$ & 68 \\
\hline Total & 14 & (8.3) & 154 & (91.7) & 168 \\
\hline
\end{tabular}

\section{Discussion}

Previous investigators have found an association between overweight and asthma severity and control, quality of life, increased medication use, and utilization of health care resources (Belarmich, 2000; Gold et al., 2003; Quinto, 2011); however, there is lack of data regarding children hospitalized with asthma who are overweight or obese. There is also lack of information regarding the clinical practices related to overweight and obesity for this population. .

Previous studies looking at the association between asthma and overweight have focused on children in the well clinic, emergency department, or intensive care setting. This study is unique in the inclusion of children admitted with asthma to the hospital general floor, as well as 
the intensive care. The prevalence of obesity and overweight in this sample (32.9\%) is similar to the prevalence of overweight and obesity in the general population at the time of the study (31.8\%) (Ogden, Carroll, Kit, \& Flegal, 2014). The prevalence of obesity in the sample, compared to obesity in the general population, was also similar with $19.6 \%$ of the sample obese and $16.9 \%$ of the general population obese (Ogden et al., 2014). These results are surprising in light of other studies that have found a higher prevalence of overweight and obesity in children who have asthma (Black, Smith, Porter, Jacobsen, \& Koebnick, 2012; Cottrell et al., 2011; Sah et al., 2013).

This study adds to the knowledge of disease process regarding children with asthma who have overweight or obesity. In this study of children hospitalized for asthma, patient age was found to differ statistically by weight group $(p<0.001)$. Healthy weight participants averaged 1.7 years younger than overweight participants $(p=0.008)$ and 2.3 years younger than obese participants $(p<0.001)$. Underweight participants were also 3.0 years younger than overweight participants $(p<0.001)$ and 3.6 years younger than obese participants $(p<0.001)$. Although the study was not longitudinal, data suggest the development of overweight and obesity with age, and lends support to the importance of recognizing and treating overweight in younger children. A recently published longitudinal study of healthy children by Cunningham, Kramer and Narayan (2014) demonstrated that overweight children at age 5 were more likely to be obese at age 13 than healthy weight children. A longitudinal study of children with asthma and overweight is needed to further analyze the relationship of asthma and the development of obesity with age.

This study further adds to the knowledge of disease process and health care for children by demonstrating a relationship of chronic asthma severity and weight group that was significant 
in the older age category $(p=0.033)$. Although a large prospective study by Peters et al., (2011) demonstrated no significant difference in chronic severity among weight groups, other studies have shown that children with asthma who are overweight or obese have more asthma morbidity (Belamarich et al., 2000; Black et al., 2012; Carroll et al., 2007; Flores et al., 2009). The current study specifically suggests an association of severe persistent asthma with obesity in older subjects. A longitudinal study would be needed to further understand this association. A difference in chronic severity for children with obesity in the older aged subjects supports the importance of recognizing, preventing, and treating overweight at any age, but may point towards early intervention to prevent progression of weight and asthma severity.

Arguably, the most important knowledge added by this study is the demonstration of the lack of recognition, diagnosis, and treatment of overweight and obesity in children who are hospitalized with asthma. The importance of monitoring BMI is supported in the literature (Barlow, 2007; Murray \& Battista, 2009; Young et al., 2011); however, investigators have reported the lack of BMI monitoring of all children in all settings, including the inpatient setting (Sleeper et al., 2009; Larsen et al., 2006; Children's Hospital Association, 2014). This study focuses on recognition of BMI percentile in children hospitalized specifically with asthma. In this study there was an obvious lack of recognition by providers of BMI percentile during the admission for all weight groups. In children, weight or BMI alone is not enough to determine weight group. Calculating the BMI percentile based on age, gender, height and weight is necessary to determine overweight and obesity. During the study, the institution was in the process of implementing the use of the electronic health record and the BMI percentile was not part of the growth chart application. This necessitated calculation by the providers to determine 
the BMI percentile and likely contributed to the fact that the BMI percentile was only recognized in $3.3 \%$ of all subjects in the sample.

It is important to note that BMI percentile was recognized in a higher percentage of subjects with obesity $(11 \%)$; however BMI percentile was not recognized for any of the overweight subjects. The increased level of recognition of BMI percentile in subjects with obesity may indicate the ability to recognize obesity during physical exam but the inability to recognize overweight by physical exam alone. This demonstrates the importance of monitoring BMI percentile for all children so that those with overweight are not overlooked. Misperception of weight status by children and the parents of children with BMI percentile between the $85^{\text {th }}$ and $95^{\text {th }}$ percentile has been reported. (Taveras et al., 2011; Edwards, Pettingall, \& Borowski, 2010). Identifying BMI percentile and educating families about BMI percentile are necessary first steps for health care providers to raise patient and parental awareness of weight status and risk of overweight and obesity.

Even when obesity was recognized in this study, the provider did not always identify it as a discharge diagnosis. At the time of discharge only $5.4 \%$ of overweight or obese patients were diagnosed with overweight or obesity. Any diagnostic label reflecting overweight or obesity was accepted as evidence of diagnosis. Barlow (2007) discussed the sensitivity of patients and families to terms reflecting overweight or obesity and recommended that the sensitivity of the patient and family be considered when diagnosing the condition. As in recognition of BMI percentile, only patients with obesity were given a diagnosis reflecting overweight or obesity. None of the subjects with overweight were given a diagnosis of overweight at the time of discharge possibly due to lack of recognition. However, lack of recognition could also be due to concern for patient or family sensitivity to the issue or lack of education of the provider. It is not 
known if the providers at the institution have had educational intervention regarding recognition and diagnosis of overweight or obesity or if overweight or obesity is recognized when patients are admitted for other diagnosis. Further study is warranted to determine why providers did not make the diagnoses.

Although current recommendations by the Expert Committee are focused on the primary care setting, identification of overweight, as well as obesity, is crucial for health and should occur in all healthcare settings. A study by Halfon, Larson, and Slusser (2013) demonstrated that children with obesity were more likely to have school problems and missed school days, attention deficit hyperactivity disorder, conduct disorder, depression, learning disability, developmental delay, orthopedic problems, asthma, allergies, headaches, and ear infections as well as asthma. Children with obesity also progress to develop hypertension, hyperlipidemia, and type II diabetes mellitus.

Treatment for overweight and obesity, as evidenced by counseling regarding healthy eating and exercise or referral to a weight management program, was lacking for subjects who were overweight or obese. Only $8.3 \%$ of the subjects with overweight and obesity received treatment for overweight or obesity. It should be noted that $14 \%$ of the obese subjects received treatment while $0 \%$ of the overweight subjects received treatment. This is consistent with lack of provider recognition and diagnosis of overweight and obesity. Dietitians were rarely consulted to address overweight or obesity. At the time of the study there was not a plan in place for routine referral to the dietitian for overweight and obese patients. The level of dietitian staffing at the hospital was not established to support the number of consults that would have been needed.

The results indicate that provider physicians and nurse practitioners rarely gave advice regarding healthy eating and exercise or referred subjects to weight management programs. In 
the study setting, the electronic discharge instructions gave the provider the option for resuming regular diet or an option for "other" in which diet directions had to be manually entered. Nearly all subjects were given directions to resume regular diet regardless of weight group. In this study healthy weight subjects were significantly younger than overweight and obese subjects.

Providing nutrition instruction and referral to families of children of all ages has the potential to prevent the development of overweight and obesity and encourage weight management. A recent study by Jenson et al., (2013) demonstrated that diet-induced weight loss can achieve improvement in asthma symptoms and quality of life. Successful weight loss likely depends upon ongoing treatment. Lack of treatment resources may have contributed to lack of outpatient referral. Options for outpatient treatment of overweight and obesity are lacking in the area of the Midwest hospital study setting and treatment is poorly covered by insurance. Understanding the reasons for lack of management and referral could be a direction of further study.

This study has given insight to many opportunities for improving the care of children with overweight and obesity admitted to the hospital for asthma however the improvements are likely applicable to all children admitted to the hospital. Young et al. (2011) recommended consistent identification and treatment as the standard of care for all children's hospitals. As outlined by Young et al. (2011), the inpatient process should start with identification of BMI percentile followed by healthy diet, assessment and treatment, education and follow-up. This is in line with the Expert Committee guidelines (Barlow, 2007) for BMI monitoring, healthy eating, exercise and activity, laboratory monitoring and referral. Currently, the Expert Committee guidelines are aimed at the outpatient setting, but the recommendations are appropriate for all health care settings. See Appendix Table A2 for a table summary of the Expert Committee recommendations. 
Recognizing overweight and obesity in the inpatient setting provides the opportunity to connect the patient and family into outpatient services for overweight and obesity. Collaboration and communication with primary care and specialty providers are essential. This communication may facilitate the scheduling of outpatient laboratory and follow-up care as recommended in the Expert Committee guidelines. Per the guidelines, care is based on BMI percentile and risk factors for diabetes and heart disease. The discharge instructions can be utilized as an important tool in documentation and communication of the plan of care.

The results of this study will be utilized in the planning process to optimize the care of children admitted to the hospital with asthma. To improve care, it will be necessary to adapt the current process of caring for children hospitalized with asthma that is based on the NAEPP guidelines (2007) to include the Expert Committee guidelines for the care of children with overweight and obesity (Barlow, 2007). A recent study by Cygan, Baldwin, Chehab, Rodriguez, and Zenk (2014) suggests that a management of pediatric overweight and obesity in the primary care setting is improved with a systematic approach that includes patient education and selfmanagement support, practice protocols and training for providers, electronic medical record system changes to support guideline-based care, and delivery system re-design. A similar system also has the potential to improve inpatient care and would also depend on the use of information technology. There are many possible opportunities for the use of electronic alerts or automated ordering based in the electronic health record to optimize the asthma care pathway to include the care of children with overweight and obesity. Upgrading the electronic health record to include automatic population of BMI percentile in the provider note and provider alerts for overweight and obesity have the potential to assist providers in assessment, diagnosis, and treatment of overweight and obesity. The provider alert for BMI percentile indicating overweight or obesity 
could also give the recommendations for gathering key information in the review of systems and history, and suggestions for the ordering of laboratory testing based on cardiac risk factors.

Once the parameters for consulting the inpatient dietitian are established by the key stakeholders, it could be possible to electronically alert the dietitian for consultation. The short length of stay for most asthma patients makes it difficult for involving the inpatient dietitian. Referral to an outpatient dietitian could be facilitated by the inpatient dietitian if indicated.

The hospital resource center could be alerted to provide pre-determined healthy eating and exercise education materials. The asthma discharge instruction templates, as well as discharge instruction templates for all diagnoses, could be modified to auto-populate BMI percentile on the discharge instructions, alert the provider to include a weight diagnosis, and include a healthy eating option to replace the current direction to return to regular diet.

Establishing a plan to monitor provider adherence to the monitoring of BMI percentile as an outcome measure in addition to the current CAC metrics could help to assure consistency in recognition, diagnosis, and treatment. Education of providers and staff will be crucial in this process change. Communicating with the primary care provider and specialty clinic regarding weight monitoring and management will prevent redundancy in health care utilization and improve consistency in care for the patient and family after discharge in keeping with the health care home concept.

Overall length of stay and admission to the pediatric intensive care unit were used in this study as indicators of increased severity of the acute episode. Although acute severity measures were not significant in this study, subjects with obesity demonstrated increased length of stay that approached significance $(p>0.057)$. Subjects with obesity also had a higher prevalence of admission to the pediatric intensive care unit (29\%) when compared with healthy weight subjects 
(18.8\%); however, this did not reach a level of significance. It should be considered that length of stay and admission to the intensive care unit may be insensitive measures of the severity of the episode. Carroll, et al., (2006) found that obese children received longer courses of supplemental oxygen, continuous albuterol and intravenous steroids in the intensive care unit. Objective assessment data like oxygen saturation, peak flow measurement, asthma score or pulmonary function studies were not gathered or reported in this study and may have contributed to the understanding of the severity of the episode of the subjects. Including other objective parameters in future studies might help to better define the effect of weight on severity of the acute episode.

The results of this study will be the building blocks for improving the process of caring for children with overweight and obesity who are admitted for asthma. Disseminating the results of this study has the potential to alert inpatient and outpatient providers to the missed opportunity of recognizing and treating overweight and obesity in children admitted with asthma and raise awareness about the relationship of these two serious health issues for children. The study gives the baseline information necessary for providers to collaborate with administration, the quality team, and the IT teams to determine, implement, and evaluate a plan for improved care. The ultimate goal is that children with asthma will benefit from optimized care.

\section{Barriers and Limitations}

\section{Barriers}

This project is timely because it focuses on two chronic health conditions of children that impact wellness and utilization of healthcare dollars (CDC, 2011; CDC, 2012). This project has the potential to impact both the prevention and management of overweight and obesity in children with asthma and could be part of the clinical quality measures for meaningful use health outcomes in the electronic health care record incentive program. However, demands on the 
hospital IT and Quality Teams affected the timing of the work on the project. A barrier encountered was the fact that not only was the BMI percentile not able to be populated electronically for the purposes of this study, but BMI percentile was not easily available in the electronic record to providers caring for patients during the time of the study. The results indicate a lack of awareness of BMI percentile by providers. Changes to the electronic record may improve recognition but will add to the workload of the IT team. Continued collaboration and planning will be necessary to make the work involved efficient.

Lack of programs for children with overweight and obesity are also a challenge for this project. It is obvious that solving the issue of overweight and obesity in children hospitalized with asthma does not stop with appropriate recognition of overweight and obesity. Recognition is only the beginning. Prevention and management in the outpatient setting after discharge is crucial and resources for community providers are lacking. Currently the institution does not have an outpatient program to address overweight and obesity and programs in the community are lacking. This impacts the provider's ability to refer for treatment. According to the Children's Hospital Association, 2013 Survey Findings of Children's Hospitals Obesity Services (2014), 55\% of the children's hospitals responding to the survey are incorporating comprehensive weight management into their strategic plan. The findings of this study will support the need for children's hospitals to identify and treat children with overweight and obesity. Without treatment, the problem will affect not only asthma but overall health of the child into adulthood.

Unfortunately, payment and reimbursement will remain a challenge. The Children's Hospital Association (2014) survey found that 84 percent of the clinics and programs reported a loss in 2012, with 15 percent breaking even and only 1 percent making a profit. Policy regarding 
reimbursement for obesity related care will be crucial to the success of weight management programs and services. Continued outcome tracking will be necessary to prove the effect of managing childhood overweight on adult health issues and costs.

\section{Limitations}

This study had several potential limitations. Throughout the study, the quality of the data was limited by the quality and completeness of the documentation by the providers. The data represented a convenience sample of the subjects admitted in 2012 to a Midwest children's hospital and therefore does not describe children who were seen in a primary care setting, discharged from the emergency room to home, or seen in a specialty care setting.

Although the data in this study were representative of the race/ethnicity of the population cared for at this urban Midwestern children's hospital, it varied from the general population in the United States at the time of the study. Specifically, it did not include many Hispanic participants. This could be considered to be a limitation in generalizing the results. Recent studies have demonstrated that the association between asthma and obesity varies with race/ethnicity. Although the association has varied widely in studies, race/ethnicity has been shown to influence both the prevalence of asthma and asthma control. (Borrell, 2013; Black, 2012).

Another limitation involved the anthropomorphic data. Although the ability to utilize BMI percentiles for data analysis was a strength of the study, the lack of height and weight measurement data or implausible data necessitated the removal of 23 subjects $(4.3 \%)$ from the analysis. There was also the possibility of unreliability in the height and weight measurements of the 510 subjects that were included in the study. Reliability of the data could have been influenced by the skill of the technician or attention to accurate recording of the 
anthropomorphic data. The retrospective nature of the methodology prevented the ability to assure the process for accurate measurement of height and weight for the subjects.

Retrospective methodology influenced the ability to gather detailed information about chronic asthma characteristics and risk for severity for the subjects. Although chronic asthma severity was identified in 501 of the 510 subjects in the sample, other details about asthmaspecific characteristics such as Asthma Control Test ${ }^{\mathrm{TM}}$ score, lung function, previous admission, previous emergency visits, asthma quality of life score, environmental exposure and family history were not consistently available in the electronic health records.

The sample size proved to be a limitation in the analyses of weight and severity by age. When the sample was broken down into age groups to assess the effect of age on weight and severity, there were small and uneven numbers in some of the categories. This precluded the ability to validly analyze all of the possible relationships.

In this study there were no underweight subjects in the older age group. Data from the CDC show that 3.6\% of children 12-19 years old were underweight in 2011-2012 (Fryar and Ogden, 2014). Lack of underweight subjects in the older age group in this study prevented the ability to compare underweight to other weight groups in the older age category or further analysis of this association.

Underweight and healthy weight subjects were significantly younger than overweight and obese subjects in this study. It is not known if asthma contributed to increased weight or lack of exercise. A longitudinal study could be considered to determine if there is similar or more significant systematic development of obesity in children with asthma compared to otherwise healthy children. 


\section{Application to Clinical Practice}

The goal of this project was to gather data to support the need for practice changes to improve the care of children with overweight or obesity who are admitted to the hospital with asthma. The results demonstrate the lack of monitoring and managing of overweight and obesity and support the need for practice change. Also important is the relationship of obesity and severity of asthma in the older group adding emphasis to the importance of recognition and treatment of overweight to prevent the development of obesity and more severe asthma. The stakeholders that were involved to conduct the study will be needed to determine and support the details and dissemination of the practice change. Per the review of literature, utilization of a systematic approach as described by Cygan et al. (2014) could be utilized to "refreeze" (Lewin, 1974) the change in practice to recognize and manage overweight and obesity.

Dissemination of the results and practice change by presentation locally and nationally as well as written publication is planned. Gathering attention for the importance of the practice change will gain support for broader policy change. Advocacy for incorporation of prevention, monitoring and management of overweight and obesity into the NAEPP guidelines for the care of children with asthma could have broad impact on the health and wellness of children with asthma. Encouraging The Expert Committee to address the care of children in all health care settings in the recommendations on childhood obesity could bridge the gap for children who are receiving care in settings other than primary care.

\section{Application of the Essentials of Doctoral Education for Advanced Nursing Practice}

$$
\text { As stated in The Essentials of Doctoral Education for Advanced Nursing Practice }
$$

(American Association of Colleges of Nursing (AACN), 2006), it is the role of the DNP to "assess the impact of practice policies and procedures on meeting the health needs of the patient 
population with whom they practice" (p. 10). This project exemplifies reviewing the practice policies in place for caring for children hospitalized with asthma to understand the effectiveness of current practice for children admitted with asthma who are overweight and obese. It is known that there is lack of emphasis on recognition and management of overweight and obesity in the asthma practice guidelines in general, and this study demonstrated a lack of recognition and management in practice in this inpatient setting.

The Essentials of Doctoral Education for Advanced Nursing Practice (AACN, 2006) further emphasize the important role of the advanced practice nurse in taking "accountability for the quality of healthcare and patient safety for the population with whom they work" (p. 10). The data from this project provide the advanced practice nurse with evidence that supports practice change. The Essentials document encourages the advanced practice nurse to evaluate care delivery and develop "approaches that meet the current and future needs of patient populations based on scientific findings (p.10)" (2006). Not only does this project support change in the institutional approach and policy, but supports broader policy change. As recommended in the AACN document, the Doctor of Nursing Practice is in a position to advocate policy change at all levels. Incorporating prevention, recognition and management of overweight and obesity into the asthma guidelines for children in all health care settings has the potential to improve the health of many children and decrease the utilization of healthcare resources. The DNP is in a position to promote recognition of overweight and obesity as best practice for care of children with asthma but should be inclusive of all children.

\section{Conclusion}

The results of this study demonstrate lack of provider recognition, diagnosis and treatment of overweight and obesity when children are hospitalized for treatment of asthma. 
There was a significant association between severe persistent chronic asthma and obesity for children in the oldest age group. This research supports the importance of weight recognition and management in the care of children with asthma as well as longitudinal research of BMI progression among children with asthma. This study lays the groundwork for practice change and outcome monitoring. Improving the care of children with overweight and obesity who are hospitalized with asthma has the potential to improve the quality of life for many children and their families. 


\section{References}

Akinbami, L. J., Moorman, J. E., \& Liu, X. (2011). Asthma prevalence, health care use, and mortality: United States, 2005-2009. National health statistics reports; no 32. Hyattsville, MD: National Center for Health Statistics. 2011. Retrieved from: http://www.cdc.gov/nchs/data/nhsr/nhsr032.pdf

American Association of Colleges of Nursing. (2006). The essentials of doctoral education for advanced nursing practice. Retrieved from http://www.aacn.nche.edu/publications/position/dnpessentials.pdf

Banasiak, N. C., \& Meadows-Oliver, M. (2004). Inpatient asthma clinical pathways for the pediatric patient: An integrative review of the literature. Pediatric Nursing, 30(6), 447450.

Barlow, S. E. (2007). Expert committee recommendations regarding the prevention, assessment, and treatment of child and adolescent overweight and obesity: Summary Report. Pediatrics, 120, S164-192.

Belarmich, P. F., Luder, E., Kattan, M., Mitchell, H., Islam, S., Lynn, H., \& Crain, E. F. (2000). Do obese inner-city children with asthma have more symptoms than nonobese children with asthma? Pediatrics, 106, 1436-1441.

Black, M. H., Smith, N., Porter, A. H., Jacobsen, S. J., \& Koebnick, C. (2012). Higher prevalence of obesity among children with asthma. Obesity, 20, 1041-1047.

Borgmeyer, A., Gyr, P.M., Jamerson, P., \& Henry, L.D. (2008). Evaluation of the role of the pediatric nurse practitioner in an inpatient asthma program. Journal of Pediatric Health Care, 22(5), 273-81. doi: 10.1016/j.pedhc.2007.07.004 
Borrell, L. N., Nguyen, E. A., Roth, L. A., Oh, S. S., Tcheurekdjian, H., Sen, S., . . Burchard, E. G. (2013). Childhood obesity and asthma control in the gala II and sage II studies. American Journal of Respiratory and Critical Care Medicine, 187, 697-702.

Carmargo, C. A., Weiss, S. T., Zhang, S., Willett, W. C., \& Speizer, F. E. (1999). Prospective study of body mass index, weight change, and risk of adult-onset asthma in women. Archives of Internal Medicine, 159(21), 2582-2588.

Carroll, C. L., Bhandari, A., Zucker, A. R., \& Schramm, C. M. (2006). Childhood obesity increases duration of therapy during severe asthma exacerbations. Pediatric Critical Care Medicine, 7(6), 527-531.

Carroll, C. L., Stoltz, P., Raykov, N., Smith, S. R. \& Zucker, A. R. (2007). Childhood overweight increases hospital admission rates for asthma. Pediatrics, 120, 730-740.

Centers for Disease Control and Prevention. (2011). Asthma in the US. Vital Signs, May 2011. Retrieved from http://www.cdc.gov/VitalSigns/Asthma/index.html

Centers for Disease Control and Prevention. (2012). Overweight and obesity. Retrieved from http://www.cdc.gov/obesity/adult/causes/index.html

Children's Hospital Association (2014). 2013 Survey Finding of Children's Hospitals Obesity Services. Retrieved from www.childrenshospitals.net/obesitysurvey

Chisolm, D. J., MAlearney, A. S., Veneris, S., Fisher, D., Holtzlander, M., McCoy, K. S. (2006) The role of computerized order sets in pediatric inpatient asthma treatment. Pediatric Allergy and Immunology, 17(3), 199-206. 
Cincinatti Children's Hospital Medical Center. (2010). Acute Asthma Guideline: Guideline for management of acute asthma exacerbation in children: Asthma Exacerbation in Children Pediatric Evidence Based Care Guidelines. Retrieved from $\underline{\text { www.cincinattichildrens.org/workarea/linkit.aspx } \text { ?inkidentifier=id\&itemid=87871\&libid }}$ $=87559$

Cottrell, L., Neal, W. A., Ice, C., Perez, M. K., \& Piedimonte, G. (2011). Metabolic abnormalities in children with asthma. American Journal of Respiratory Critical Care Medicine, 183(4), 441-448. doi: 10.1164/rccm.201004-0603OC

Cunningham, S. A., Kramer, M. R., \& Narayan, V. (2014). Incidence of childhood obesity in the United States. New England Journal of Medicine, 370, 403-411.

Cygan, H. R., Baldwin, K., Chehab, L. G., Rodriguez, N. A. \& Zenk, S. N. (2014). Six to success: improving primary care management of pediatric overweight and obesity. Journal of Pediatric Health Care, 28 (5), 420-437.

Edwards, N. M., Pettingall, S., \& Borowski, I. W. (2010). Where perception meets reality: selfperception of weight in overeight adolescents. Pediatrics, 125, e452-e458.

Fassl, B. A., Nkoy, F. L., Stone, B. L., Srivasta, R., Simon, T. D., Uchida, K. K., Greene, T. Cook, L. J., \& Maloney, C. G. (2012). The joint commission children's asthma care quality measures and asthma readmissions. Pediatrics, 130(3), 482-491.

Flores, G., Snowden-Bridon, C., Torres, S., Perez, R., Walter, T., Brotanek, J., Tomany-Korman, S. (2009). Urban minority children with asthma: Substantial morbidity, compromised quality and access to specialists, and the importance of poverty and specialty care. Journal of Asthma, 46, 392-398. 
Fryar, C. D. \& Ogden, C. L. (2014). Prevalence of underweight among children and adolescents aged 2-19 years: United States, 1963-1965 through 2011-2012. National Center for Health Statistics. Retrieved from: http://www.cdc.gov/nchs/data/hestat/underweight_child_07_10/underweight_child_07_1 0.pdf

Gilliland, F. D., Berhane, K., Islam, T., McConnell, R., Gauderman, W. J., Gilliland, S. S., Avol, E., \& Peters, J. M. (2003). Obesity and the risk of newly diagnosed asthma in school-age children. American Journal of Epidemiology, 158(5), 406-415.

Ginde, A. A., Santillan, A. A., Clark, S., \& Carmargo, C. A. Jr. (2010). Body mass index and acute asthma severity among childen presenting to the emergency department. Pediatric Allergy and Immunology, 21, 480-488.

Gold, D. R., Damokosh, A. J., Dockery, D. W., \& Merkey, C. S. (2003). Body-mass index as a predictor of incident asthma in a prospective cohort of children. Pediatric Pulmonology, 36(6), 514-521.

Halfon, N., Larson, K., \& Slusser, W. (2013). Associations between obesity and comorbid health, developmental, and physical conditions in a nationally representative sample of US children aged 10-17. Academic Pediatrics, 13, 6-13.

Jenson, M. E., Collins, C. E., Gibson, P. G., \& Wood, L. G. (2011). The obesity phenotype in children with asthma. Pediatric Respiratory Reviews, 12, 152-159.

Jensen, M. E., Gibson, P. G., Collins, C. E. , Hilton, J. M., \& Wood. L. G. (2013). Dietinduced weight loss in obese children with asthma: a randomized controlled trial. Clinical and Experimental Allergy, 43(7):775-84. 
Jenson, M. E., Wood, L. G., \& Gibson, P. G. (2012). Obesity and childhood asthma mechanisms and manifestations. Current Opinions in Allergy and Clinical Immunology, 12, 186-192.

Larsen, L., Mandleco, B., Williams, M., \& Tiedeman, M. (2006). Childhood obesity: Prevention practices of nurse practitioners. Journal of the American Academy of Nurse Practitioners, $18,70-79$.

Lewin, K. (1974). Frontiers in human dynamics in the management of organisations. M. L. Tushman (Ed.). London: Harper Row.

McAlearney, A. S., Chisolm, D., Veneris, S., Rich, D., \& Kelleher, K. (2006). Utilization of evidence-based computerized order sets in pediatrics. International Journal of Medical Informatics, 75, 501-512. Doi:10.1016/j.ijmedinf.2005.07.040

Merrill, C.T., Stranges, E., \& Steiner, C. (2008). Hospital stays for asthma among children, 2006. Agency for Healthcare Research and Quality Healthcare Cost and Utilization Project Statistical Brief, 58. Retrieved from http://www.hcupus.ahrq.gov/reports/statbriefs/sb58.pdf

Moorman, J. E., Rudd, R. A., Johnson, C. A., King, M., Minor, P., Bailey, C., Scalia, M. R., \& Akinbami, L. J. (2007). National Surveillance for asthma: United States, 1980-2004. Morbidity and Mortality Weekly Report, Surveillance Summaries, 56(SS08), 1-4; 18-54. Retrieved from: http://www.cdc.gov/mmwr/preview/mmwrhtml/ss5608a1.htm Moorman, J. E., Akinbami, L. J., Bailey, C. M., Zahran, H. S., King, M. E., Johnson, C. A., \& Liu, X. (2012). National Surveillance of asthma: United States, 2001-2010. National Center for Health Statistics. Vital Health Stat, 3(35). 2012. Retrieved from: http://www.cdc.gov/nchs/data/series/sr_03/sr03_035.pdf 
Munasinghe, R. L., Arsene, C., Abraham, T. K., Zidan, M., \& Siddique, M. (2011). Improving the utilization of admission order sets in a computerized physician order entry system by integrating modular disease specific order subsets into a general medicine admission order set. Journal of the American Medical Informatics Association, 18, 322-326. doi:10.1136/amiajni-2010-000066

Murray, R., \& Battista, M. (2009). Managing the risk of childhood overweight and obesity in primary care practice. Current Problems in Pediatric Adolescent Health Care, 39, 146165.

National Heart, Lung, and Blood Institute. National Asthma Education and Prevention Program. Expert Panel Report 3: Guidelines for the Diagnosis and Management of Asthma. Summary Report 2007. Retrieved from http://www.nhlbi.nih.gov/guidelines/asthma/asthsumm.htm

Ogden, C., \& Carroll, M. (2010). Prevalence of obesity among children and adolescents: United States, trends 1963-1965 through 2007-2008. NCHS Health E-Stat, Center for Disease Control Data and Statistics. Retrieved from http://www.cdc.gov/nchs/data/hestat/obesity_child_07_08/obesity_child_07_08.pdf.

Ogden, C. L., Carroll, M. D., Kit, B. K., \& Flegal, K. M. (2012). Prevalence of obesity and trends in body mass index among US children and adolescents, 1999-2010. Journal of the American Medical Association, 307(5):483-90.

Ogden, C. L., Carroll, M. D., Kit, B. K., Flegal, K. M. (2014). Prevalence of childhood and adult obesity in the United States, 2011-2012. Journal of the American Medical Association, 311(8), 806-814. 
Orzog, P. R., \& Emanuel, E. J. (2010). Health care reform and cost control. The New England Journal of Medicine, 363, 601-603.

Papoutsakis, C., Priftis, K., Drakouli, M., Prifti, S., Konstantaki, E., Chondonikola, M., Antonogeorgos, G., \& Matziou, V. (2013). Childhood overweight/obesity and asthma: Is there a link? A systematic review of recent epidemiologic evidence. Journal of the Academy of Nutrition and Dietetics, 113, 77-105.

Peters, J. I., McKinney, J. M., Smith, B., Wood, P., Forkner, E., \& Galbreath, A. D. (2011). Impact of obesity in asthma: evidence from a large prospective disease management study. Annals of Allergy, Asthma, \& Immunology, 106, 30-35.

Quinto, K. B., Zuraw, B. L., Poon, K. T., Chen, W., Schatz, M., \& Christianson, S. C. (2011). The association of obesity and asthma severity and control in children. Journal of Allergy and Clinical Immunology, 128(5), 964-969.

Rance, K. (2011). Obesity and asthma: A dangerous link in children: An integrative review of the literature. The Journal for Nurse Practitioners, 7(4), 287-292.

Rao, G. (2008). Childhood obesity: Highlights of AMA expert committee recommendations. American Family Physicians, 78(1), 57-63.

Sah, P. K., Teague, W. G., Demuth, K., Whitlock, D. R., Brown, S. D., \& Fitzpatrick, A. M. (2013). Poor asthma control in obese children may be overestimated because of enhanced perception of dyspnea. Journal of Allergy and Clinical Immunology: In Practice, 1, 3945.e.2.

Sithole, F., Douwes, J., Burstyn, I. \& Veugelers, P. (2008). Body mass index and childhood asthma: a linear association? Journal of Asthma, 45(6), 473-477. 
Shaheen, S. O., Sterne, J. A., Montgomery, S., M., \& Azima, H. (1999). Birth weight, body mass index and asthma in young adults. Thorax, 54(5), 396-402.

Sleeper, E. J., Ariza, A. J., \& Binns, H. J. (2009). Do hospitalized pediatric patients have weight and blood pressure concerns identified? The Journal of Pediatrics, 154(2), 213-217.

The Joint Commission. (2011). Children's Asthma Care. Retrieved from http://www.jointcommission.org/childrens_asthma_care/

Tanda, R. \& Salsberry, R. (2014). The impact of the 2007 expert committee recommendations on childhood obesity preventive care in primary care settings in the United States. Journal of Pediatric Health Care, 28 (3), 241-250.

Taveras, E. M., Hohman, K. H., Price, S., Rifas-Shiman, S. L., Mitchell, K., Gortmaker, S. L., \& Gilman, M. W. (2011). Correlates of participation in a pediatric primary care-based obesity prevention intervention. Obesity, 19 (2), 449-452.

Taylor, B., Mannino, D., Brown, C., Crocker, D., Twum-Baah, N., \& Holguin, F. (2008). Body mass index and asthma severity in the national asthma survey. Thorax, 63(1), 14-20.

Young, K. L., Demeule, M., Stuhlsatz, K., Janzen, D., Porter, R. M., Pomettio, M., . . Peterson, T. (2011). Identification and treatment of obesity as a standard of care for all patients in children's hospitals. Pediatrics, 128, S2, S47-50. 


\section{Appendix A}

Table A1

Demographic and Asthma Characteristics of Children Hospitalized with Asthma

\begin{tabular}{|c|c|c|c|c|c|c|}
\hline & $\begin{array}{c}\text { Entire } \\
\text { Group } \\
(\mathrm{N}=510)\end{array}$ & $\begin{array}{c}\text { Obese } \\
(\mathrm{N}=100)\end{array}$ & $\begin{array}{c}\text { Over- } \\
\text { weight } \\
(\mathrm{N}=68)\end{array}$ & $\begin{array}{l}\text { Healthy } \\
\text { Weight } \\
(\mathrm{N}=314)\end{array}$ & $\begin{array}{l}\text { Under- } \\
\text { weight } \\
(\mathrm{N}=28)\end{array}$ & $p$-value \\
\hline \multicolumn{7}{|l|}{ Demographic factors } \\
\hline Age (yr), mean (s.d.) & $8.4(3.8)$ & $10.1(3.7)$ & $9.5(3.9)$ & $7.8(3.6)$ & $6.5(2.5)$ & $<0.001 *$ \\
\hline \multicolumn{2}{|l|}{ Gender (n (\%)) } & & & & & 0.500 \\
\hline Male & $321(62.9)$ & $65(65.0)$ & $43(63.2)$ & $192(61.1)$ & $21(75.0)$ & \\
\hline Female & $189(37.1)$ & $35(35.0)$ & $25(36.8)$ & $122(38.9)$ & $7(25.0)$ & \\
\hline \multicolumn{2}{|l|}{ Race/Ethnicity (n (\%)) } & & & & & 0.988 \\
\hline Caucasian & $98(19.2)$ & $17(17.0)$ & $13(19.1)$ & $61(19.4)$ & $7(25.0)$ & \\
\hline African American & $387(75.9)$ & $77(77.0)$ & $52(76.5)$ & $238(75.8)$ & $20(71.4)$ & \\
\hline Asian & $3(0.6)$ & $1 \quad(1.0)$ & $0 \quad(0.0)$ & $2(0.6)$ & $0 \quad(0.0)$ & \\
\hline Other & $17(3.3)$ & $3 \quad(3.0)$ & $2(2.9)$ & $11(3.5)$ & $1 \quad(3.6)$ & \\
\hline Unknown & $5(1.0)$ & $2(2.0)$ & $1(1.5)$ & $2(0.6)$ & $0 \quad(0.0)$ & \\
\hline \multicolumn{2}{|l|}{ Insurance Status (n (\%)) } & & & & & 0.366 \\
\hline Government & $339(66.7)$ & $69(69.7)$ & $43(63.2)$ & $207(66.1)$ & $20(71.4)$ & \\
\hline Commercial & $150(29.5)$ & $28(28.3)$ & $19(27.9)$ & $96(30.7)$ & $7(25.0)$ & \\
\hline Self-Pay & $19 \quad(3.7)$ & $2(2.0)$ & $6 \quad(8.8)$ & $10(3.2)$ & $1 \quad(3.6)$ & \\
\hline \multicolumn{7}{|l|}{ Asthma Characteristics } \\
\hline \multicolumn{2}{|l|}{ Length of Stay (n (\%)) } & & & & & 0.057 \\
\hline 1 Day & $265(52.0)$ & $41(41.0)$ & $33(48.5)$ & $177(56.4)$ & $14(50.0)$ & \\
\hline 2-3 Days & $201(39.4)$ & $47(47.0)$ & $31(45.6)$ & $114(36.3)$ & $9(32.1)$ & \\
\hline 4 or more & $44 \quad(8.6)$ & $12(12.0)$ & $4 \quad(5.9)$ & $23(7.3)$ & $5(17.9)$ & \\
\hline \multicolumn{2}{|l|}{ Intensive Care Unit (n (\%)) } & & & & & 0.179 \\
\hline Yes & $110(21.6)$ & $29(29.0)$ & $15(22.1)$ & $59(18.8)$ & $7(25.0)$ & \\
\hline No & $400(78.4)$ & $71(71.0)$ & $53(77.9)$ & $225(81.2)$ & $21(75.0)$ & \\
\hline \multicolumn{2}{|c|}{ Chronic Asthma Severity $^{\mathrm{a}}(\mathrm{n}(\%))$} & & & & & $0.001 *$ \\
\hline Intermittent & $88(17.6)$ & $11(11.6)$ & $10(14.9)$ & $60(19.2)$ & $7(25.9)$ & \\
\hline Mild Persistent & $114(22.8)$ & $16(16.8)$ & $6 \quad(9.0)$ & $82(26.3)$ & $10(37.0)$ & \\
\hline Moderate Persistent & $211(42.1)$ & $46(48.4)$ & $32(47.8)$ & $124(39.7)$ & $9(33.3)$ & \\
\hline Severe Persistent & $88(17.6)$ & $22(23.2)$ & $19(28.4)$ & $46(14.7)$ & $1 \quad(3.7)$ & \\
\hline
\end{tabular}

${ }^{\mathrm{a}} \mathrm{N}=501$ in Chronic Severity analysis. (Nine subjects were removed due to lack of chronic severity data.)

* Statistically significant at $p<0.05$ 
Appendix Table A2

\begin{tabular}{|c|c|c|c|}
\hline \multicolumn{4}{|c|}{ Prevention and Treatment of Childhood Overweight and Obesity } \\
\hline \multicolumn{2}{|c|}{ Review of Symptoms } & Family History & Recommendations \\
\hline Prevention (All) & & $\begin{array}{ll}\text { - } & \text { Obesity } \\
\text { - } & \text { Type } 2 \text { DM } \\
\text { - } & \text { Hypertension } \\
\text { - } & \text { Abnormal lipid } \\
& \text { level } \\
\text { - Heart Disease }\end{array}$ & $\begin{array}{ll}\text { - } & \text { Breastfeeding } \\
\text { - } & \text { Family Meals } \\
\text { - } & \text { Limited Screen Time } \\
\text { - } & \text { Regular Physical } \\
\text { - } & \text { Activity } \\
& \text { Yearly BMI } \\
& \text { measurement }\end{array}$ \\
\hline $\begin{array}{l}\text { Prevention Plus } \\
\text { (BMI 85-94\%) }\end{array}$ & $\begin{array}{ll}\text { - } & \text { Snoring/Sleep } \\
\text { - } & \text { Menstrual } \\
\text { irregularity } \\
\text { - } \text { Hip, knee or leg } \\
\text { pain } \\
\text { - } \\
\text { - } \\
\text { - } \\
\text { Dhirst } \\
\end{array}$ & - As Above & $\begin{array}{l}\text { Daily } \\
\text { - } \quad \mathbf{5} \text { Servings fruits/veg } \\
\text { - } \quad \leq 2 \text { hrs screen time } \\
\text { - } \quad \geq 1 \text { hr physical } \\
\text { activity } \\
\text { - } \quad \text { 0 sugared drinks } \\
\text { - } \quad \text { Healthy breakfast } \\
\text { - } \quad \text { Limited eating out, } \\
\quad \text { prepare own food }\end{array}$ \\
\hline $\begin{array}{l}\text { Structured } \\
\text { Weight } \\
\text { Management } \\
\text { (BMI 95-98\%) }\end{array}$ & - As Above & - As above & $\begin{array}{l}\text { Written diet and } \\
\text { exercise } \\
\text { Frequent follow- } \\
\text { up }\end{array}$ \\
\hline $\begin{array}{l}\text { Comprehensive } \\
\text { Multidisciplinary } \\
\text { Intervention } \\
\text { (Failure of } \\
\text { structured weight } \\
\text { management after } \\
\text { 3-6 mos) }\end{array}$ & - As Above & - As Above & $\begin{array}{l}\text { - Frequent visits with } \\
\text { MD/APN \& RD } \\
\text { Consider exercise } \\
\text { and behavior } \\
\text { specialists }\end{array}$ \\
\hline $\begin{array}{l}\text { Tertiary Care } \\
\text { Intervention } \\
\text { (BMI >99\% or } \\
\text { failure of above) }\end{array}$ & - As Above & - As Above & $\begin{array}{ll}\text { - } & \text { Meal replacement } \\
\text { - } & \text { Pharmacotherapy } \\
\text { - } & \text { Bariatric surgery }\end{array}$ \\
\hline \multicolumn{4}{|c|}{$\begin{array}{l}\text { If BMI } 85 \% \text { and above, Physical Exam should include: blood pressure, acanthosis nigricans, tonsils, goiter, tender } \\
\text { abdomen, liver, bowing of legs, limited hip range of motion, optic discs if headache, and hirsutism. Note: blood } \\
\text { pressure may be influenced by albuterol and steroids necessary for treatment of asthma. Follow-up of elevated } \\
\text { blood pressure at follow-up appointment is recommended. }\end{array}$} \\
\hline \multicolumn{4}{|c|}{$\begin{array}{l}\text { Screening Laboratory Tests recommended for BMI } 85 \% \text { and above: Fasting lipid profile. If age } 10 y \text { and above, } \\
\text { and other risk factors, fasting glucose, ALT \& AST biannually. Note: Laboratory tests will be influenced by steroid } \\
\text { burst necessary for treatment of asthma and therefore not recommended in acute setting. Hgb A1C may be } \\
\text { considered. }\end{array}$} \\
\hline
\end{tabular}

Source: Adapted from Barlow, S. E. (2007). Expert committee recommendations regarding the prevention, assessment, and treatment of child and adolescent overweight and obesity: summary report. Pediatrics, 120, S164-S192. 